CIENCIA Y SOCIEDAD

Volumen XXVII, Número 2

Abril - Junio 2002

\title{
MAPAS SOCIALES DE VILLA FRANCISCA Y CONTEXTO \\ NEOLIBERAL: OPORTUNIDAD Y DESAFÍO PARA LA INTERVENCIÓN SOCIO-EDUCATIVA
}

Miguel Angel Moreno Hernández*

\section{RESUMEN}

En la actualidad, numerosos procesos socio-educativos de base en escuelas públicas de República Dominicana, propician una auténtica vinculación entre los centros educativos y sus entornos comunitarios. Este acercamiento ofrece dimensiones insospechadas acerca de la realidad de niños, niñas y adolescentes (NNA), que el trabajo de aula por sí solo no permite. Desde este ámbito profesional, el trabajo de acompañamiento e investigación pedágógica desde la universidad sede, ofreció la oportunidad de participar con el equipo docente de la escuela República del Uruguay en Villa Francisca (Santo Domingo).

PALABRAS CLAVES:

Educación, sociología, neoliberalismo

Cak rografia oficial y mapas socialles de Villa Francisca

A medio camino entre la tradición de la Zona Colonial de Santo Domingo, y el paso elevado más largo de la ciudad, en la avenida 27 de Febrero, el sector de Villa Francisca desarrolla su vida cotidiana entre el trasiego caótico de la zona de más alta

(*) Área de Humanidades - INTEC 
concentración comercial -de carácter formal- del país, y la recóndita calma, casi pueblerina, de otras calles ajenas a ese devenir humano. Por su ubicación geográfica y las características de los contrastes socio-económicos que se dan en su seno, el sector de Villa Francisca constituye un claro exponente de los procesos de rediseño urbano realizados a espaldas de las necesidades humanas.

Situada en una encrucijada histórica de la ciudad de Santo Domingo, Villa Francisca limita al Sur con el barrio de San Lázaro y Santa Bárbara (donde arranca la zona Colonial), al Este con el mismo río Ozama, que baña la capital dominicana, al Norte con Villa María y Mejoramiento Social, y al Oeste, con San Carlos y Villa Consuelo, aunque, como veremos, ninguno de estos límites de la cartografía oficial, son asumidos por los propios vecinos y vecinas del sector.

Según datos de la Oficina Nacional de Estadística (ONE), su superficie es de $1,025 \mathrm{Km}^{2}$ (VII Censo nacional de población y vivienda), y una población de 30,859 habitantes, para una densidad de 30.11 personas/ hectárea, dato matizado según las zonas, altamente diferenciadas, del sector.

Según informaciones de prensa recogidas por De la Cruz y Santana (2000), el nombre de Villa Francisca

“[...] data desde el 1876, pues, según datos históricos, el poeta Manuel de Jesús Galván era propietario de una estancia de descanso y le puso el nombre de su primera esposa Francisca Velásquez. Estos terrenos formaban parte de las plantaciones de caña de azúcar que fueron inhabilitadas por la caída de los precios internacionales en el mercado estadounidense. Esto provocó que estos terratenientes vendieran sus parcelas para urbanización futura o para descanso".

Cabe recordar que nos estamos refiriendo al que todavía era, hasta bien entrado el siglo XX, un sector extramuros, allende la muralla colonial, que es visible desde distintas zonas del barrio, que al hallarse situado más elevado que la zona colonial colin- 
dante permite divisar parte de las estructuras históricas, como las ruinas de la iglesia de San Francisco, desde el Parque Enriquillo.

De la Cruz y Santana (2000), citando a Marcio Veloz Maggiolo, continúan el recorrido histórico, situándonos en el año 1912, cuando

\footnotetext{
"la parte que perteneció al poeta Manuel de Jesús Galván fue comprada $[\ldots]$ por [...] don Juan Alejandro Ibarra, para impulsar un proyecto de vivienda urbanístico privado, convirtiéndose más tarde en su fundador."
}

Este fue el segundo ensanche que tuvo Santo Domingo fuera de sus murallas coloniales, después de Ciudad Nueva.

Precisamente Marcio Veloz ha sido uno de los autores criollos que, dentro de su vastísima producción, más ha recuperado señas de identidad tradicional de Villa Francisca, especialmente durante el régimen del dictador Trujillo (1930-1961), dada su extraordinaria habilidad para integrar la memoria oral, como en su obra "Trujillo, Villa Francisca y otros fantasmas", libro del año 1997 en República Dominicana.

Bajo el período de la dictadura, Villa Francisca inicia su despegue como núcleo comercial en torno a la avenida Duarte, siendo receptora de las primeras inmigraciones campesinas a Santo Domingo. En esa zona también se inicia su leyenda de zona "alegre", asociada sobre todo a la zona del barrio conocida como Borojol, a ritmo de son, alcohol, y cabaret, y hoy en franca decadencia. También bajo el trujillato se construye la escuela "Julia Molina de Trujillo", nombre de la mamá del tirano, por el cual aún hoy popularmente - "la Julia"- se conoce a la escuela "República del Uruguay", sede de nuestro trabajo de campo.

En el trujillato también se urbaniza el Parque Enrriquillo, con su gran planta de salón, a semejanza de otras plazas públicas, como el Parque Independencia, o el parque de San Pedro, en Villa Consuelo. De la misma época data la construcción de la plan- 
ta generadora de energía eléctrica de Timbeque, altamente ruidosa y contaminante, en el extremo sureste del barrio.

Posteriormente, Villa Francisca tuvo un notable protagonismo en la guerra civil de 1965, prácticamente urbana, pues en su extremo noreste, en lo que actualmente es la Plaza de la Trinitaria, frente al puente Duarte, estuvo situado uno de los frentes más activos del bando civil-constitucionalista, frente a las fuerzas acorazadas de la base aérea de San Isidro apoyadas por tropas de la OEA y los Estados Unidos. Probablemente, la construcción de la plaza de La Trinitaria, bajo el régimen de los doce años de Balaguer (1966-1978), respondiera, como en otros casos, a la necesidad de borrar todo recuerdo de aquella memorable gesta cívica, remodelando el trazado urbano con la excusa de su embellecimiento.

Como en otros barrios de la zona norte de Santo Domingo, el período de los doce años de Balaguer, caracterizado por una permanente represión de las libertades públicas, tuvo en Villa Francisca una contestación significativa, que sólo fue atenuada entrados los '90 del siglo XX, y debido a los cambios sociales vividos por la población dominicana. En el caso de Villa Francisca, la estrategia balaguerista de debilitamiento de la sociedad civil estuvo asociada, una vez más, a remodelaciones urbanas, como la que supuso la construcción de la avenida Méjico, desde el Palacio Nacional hasta el puente Mella (puente "de las bicicletas"), fragmentando en dos el corazón de los históricos y combativos barrios de San Carlos y Villa Francisca, mediante una amplia vía de tres carriles por banda, y creando una nueva frontera sur a estos barrios.

Esta estrategia de demarcación geográfica se refuerza por la construcción de "modernos" e inusuales bloques de apartamentos populares, supuestamente para compensar el déficit habitacional que provocan los desalojos, y que actúan como cortina que tapa la pobreza de los barrios que siguen quedando a su 
espalda, y en nada mejorados. La oportunidad para la apertura de la avenida Méjico, y otras en la ciudad, la constituyó la celebración, en 1992, controversial, del V Centenario de la llegada de los españoles a la isla y al continente, con ocasión de lo cual se promovió una amplia remodelación urbana, con financiamiento español, entre otros.

A principios del año 2000 se concluye otra de las remodelaciones más significativas de Villa Francisca, en su extremo norte, con la inauguración de los pasos elevados (uno en la 27 de Febrero, dirección Oeste, y otro en la París, dirección Este), que deshumanizan en gran medida una de sus zonas de por sí más deterioradas, además de simbolizar el énfasis en construcciones faraónicas del primer gobierno contemporáneo post-Balaguer (PLD, 1996-2000), frente a inversiones destinadas a la satisfacción de las necesidades humanas.

Una de las edificaciones demolidas cuya ubicación todavía hoy recuerdan los lugareños es la del Sindicato de obreros portuarios de arrimo (POASI), hoy reubicada a espaldas del Parque Enriquillo, y que simbolizaba la pujanza de la lucha sindical y de la actividad portuaria, hoy desplazada al puerto de Haina, distante más de 15 Kilómetros.

Paradójicamente, Villa Francisca no tiene comunicación directa con el río Ozama, pues toda su franja este se halla ocupada para uso industrial por las instalaciones de las plantas generadoras de electricidad de Timbeque, Sea Board, depósitos de la Compañía Dominicana de Electricidad (CDE), así como depósitos de combustible de alta capacidad, segregados del trazado urbano mediante un muro, atrás del cual es notorio el hacinamiento, al final de las calles - sin salida - del sub-sector de Borojol.

VINETTAS URBANAS DE LA ESTRATIFICACIÓN SOCIAL

Los diferentes sub-sectores en los que se divide a lo interno la realidad de Villa Francisca, según los resultados de nuestro 
trabajo de campo, tienen que ver con otras tantas formas de apropiación o sentimiento de pertenencia de sus moradores. Tomando como núcleo central del barrio el gran espacio del Parque Enriquillo, y los ejes de las avenidas Duarte (norte-sur) y Méjico (oeste-este), podríamos distinguir cinco grandes zonas física y socialmente bien diferenciadas, considerando el límite de la avenida. 27 de febrero al norte, y la avenida Méjico al sur (exceptuando una zona):

- Arteria comercial de la Duarte, Parque Enriquillo, y calles aledañas Jacinto de la Concha y José Martí.

- Al oeste de la Duarte, entre la Jacinto de la Concha y la Juan Bautista Vicini, o la 27 de febrero.

- Al este de la Duarte, desde la José Martí hasta la Vicente Noble.

- Al este de la Vicente noble, hasta el límite del río, Borojol, o Ensanche Margara.

- Al sur de la avenida Méjico, hasta la avenida Mella, y entre la calle Altagracia y el puente de las "bicicletas".

Por la configuración tan diferente del resto del barrio, los apartamentos colindantes con la avenida 27 de febrero, de los años 70's del siglo pasado, y los más recientes de la avenida Méjico, también podrían ser consideradas sub-zonas diferentes, dado el hábitat tan diferente que provocan. Igual se puede decir de la respaldo Ravelo, por la fisonomía de sus viviendas y las características de marginación, o la zona de Timbeque, unida por un laberinto de callejones y patios al final de la Ravelo. Cada una de estas zonas genera diferentes dinámicas sociales que nos resulta de interés prioritario conocer para nuestra inserción socio-educativa. 


\section{MAPA SOCIAL I - AVENIDA DUARTE}

La avenida Duarte en sí, y sus calles aledañas, tanto transversales como paralelas, es el sector de Villa Francisca donde más agudamente se observa la transformación urbanística debida a la invasión del espacio común por grandes superficies comerciales, y lo que puede marcar la evolución de todo el sector en un futuro no tan lejano. Aunque de origen familiar, varios grandes super-comercios de la avenida Duarte ocupan manzanas completas, y han expandido anexos a manzanas colindantes en las calles traseras, o bien demolido manzanas completas para estacionamiento de clientes. Como ejemplo, el mismo Parque Enriquillo ha sido transformado en menos de un lustro, adueñándose de uno de sus laterales por completo una de las mega-empresas comerciales.

Alrededor de éstas, otras instalaciones del mediano y pequeño comercio satura la extensión de la avenida Duarte, mayormente en la zona que pertenece a Villa Francisca, al sur de la avenida 27 de febrero.

Cerrando el universo de la Duarte, en su confluencia con la avenida Mella, otro gran super-comercio reproduce las características de ocupación espacial y marca el límite hacia el sur.

En otro anillo más, un sin número de vendedores ambulantes de todo tipo de productos, desde alimentos hasta ropa, calzados o libros, bordea todas las aceras de la avenida, extendiéndose hasta el Parque Enriquillo, y hasta la José Martí y la París. En estas dos últimas, la venta callejera más abundante es de hortalizas y frutas, con un alto componente de vendedores y vendedoras de origen haitiano. En diferentes lugares, la venta de comida o de cintas de cassette, es acompañada por un reclamo musical que añade mil melodías y ruidos a los que de por sí ya provocan la congestión humana y vehicular, así como los permanentes pregones de los cobradores de guagua y vendedores y vendedoras ambulantes. 
Por la densidad de la ocupación comercial, es ésta la zona más congestionada en el tránsito humano y vehicular. El entorno de la Duarte refleja, todas las formas de la cultura popular, al concentrar tradicionalmente el interés de compra de cualquier habitante del país, atraído/a por la fama de ser un lugar donde uno "halla de todo".

En la noche, este entorno es el epicentro de las trabajadoras sexuales, propiciándose un ambiente nocturno perjudicial para la salud mental y moral de NNA, que crea un clima favorable a la Explotación Sexual y Comercial (ESC) de personas menores de edad.

Las calles traseras a la avenida Duarte y espacios públicos tan significativos como el Parque Enriquillo, son ámbito habitual para las transacciones sexuales, en las que a veces participan NNA de la calle, conocidos como "palomos". En un diagnóstico que realizamos de la escuela del sector, encontramos testimonios sobre grupos de adolescentes que estarían involucradas en transacciones sexuales.

No obstante ser el centro de una actividad comercial millonaria, esta área de los grandes capitales locales de Villa Francisca, ya ha sido desplazada en los últimos veinte años, heredando la primacía, como nos recuerda César Pérez (1996), el polígono comprendido entre la John F. Kennedy, avenida 27 de Febrero, José Contreras y Winston Churchill, sectores urbanizados como ensanches de la ciudad para clase alta, y donde incluso en los últimos años se han abierto gigantescas sucursales de algunos negocios de la Duarte, tipo "multi-centro", y que aventajan con creces a su casa matriz.

La actividad comercial masiva de Santo Domingo, se hace más segregada entre los comercios de un tono más popular de la Duarte, y el ambiente más organizado y "selecto" de los supercomercios de la Churchill y 27 de Febrero, aunque éstos ya ab- 
sorben la demanda de los barrios extremos de la franja oeste de la capital.

Lo más llamativo de esta ocupación espacial y funcional en la avenida Duarte, es que, a pesar de la complejidad de las superficies comerciales, y de los recursos materiales dispuestos, el entorno urbano luce deprimente, desorganizado, anti-higiénico, y paupérrimo, como exponente de que todo este desarrollo urbano se realiza sin dejar ningún tipo de beneficio al sector en la mejora de su calidad de vida, exceptuando la generación de empleo directo (atención al público y almacén) e indirecto (talleres de manufacturas).

Respecto a las secuelas más visibles de la sobre-explotación comercial del sector, encontramos una de las más preocupantes el tratamiento de residuos sólidos producidos por las mega-empresas del pedazo, así como por los miles de viandantes que a diario realizan numerosas compras de los centenares de puestos ambulantes. A pesar de los esfuerzos recientes del ayuntamiento, es frecuente ver montañas de basura en diferentes puntos.

\section{MAPA SOCIAL II - LÍMITES DIFUSOS}

En dirección Oeste desde la avenida Duarte y hacia la 27 de Febrero, se abre un amplio sub-sector que para muchos de los habitantes de Villa Francisca ya no es tal, sino San Carlos, el barrio colindante, aunque el plano oficial de la ONE lo señala como en los límites de Villa Francisca.

Aunque tan popular como cualquier otra zona de Villa Francisca, este sub-sector no se percibe tan empobrecido, estando más equilibradas las viviendas de concreto (cemento), y las tradicionales de madera, que todavía hoy confieren su aspecto tan característico a los barrios de Santo Domingo.

En esta zona de aspecto más homogéneo hay una presencia institucional más notoria. Además del Juzgado de Paz de la 
Barahona, remodelado, la Pastoral Juvenil de la Iglesia católica tiene unas amplias instalaciones para encuentros y actividades formativas, en la esquina de la Jacinto de la Concha con la avenida Méjico, sobre el solar de lo que fue aquella inverosímil montaña de ranchitos conocida irónicamente como el "ensanche cucaracha." Al frente de este edificio para jóvenes, se encuentra la sede de la Asociación de Mayoristas de Provisiones, y cerca, una sucursal de recaudación de Rentas Internas, y una botica popular.

Otras dos instituciones representativas de la identidad barrial se hallan en este lado de Villa Francisca (¿o San Carlos?) precisamente por la presión urbanística que sufre la otra parte situada al Oeste de la avenida Duarte. Se trata de la parroquia católica de San Felipe Diácono, que estuvo situada en lo que hace tiempo ya es parqueo de un gran centro comercial, y el Club de Villa Francisca, que estaba casi colindante con el parque Enriquillo, y animaba esa zona. Como en otros casos, las grandes superficies comerciales realizaron una permuta de terrenos, construyendo incluso el nuevo edificio.

Aparentemente, una operación beneficiosa para ambas partes. Pero muchos de los vecinos de Villa Francisca, de la zona este, sienten en realidad que se llevaron su club y su iglesia, pues perciben la Duarte como línea divisoria de dos realidades. En relación a la importancia simbólica de estos desplazamientos, cabe decir que el club de baloncesto de Villa Francisca mantiene su liderato en la liga nacional de ese deporte, como único exponente de un relieve genuino del sector.

La congestión vehicular de la París con 27 de Febrero ha provocado también que el extremo más al oeste de este sub-sector sea utilizado como vía de entrada del transporte público, guagas y autobuses del Estado (la OMSA), añadiendo una peligrosidad a la seguridad de los peatones, así como a la recreación de niños y niñas en las calles Barahona y Francisco Henríquez y Carvajal. 
Al Este de la avenida Duarte, desde la José Marti hasta la Vicente Noble, se abre otro sub-sector que constituye la trastienda de la zona comercial de la Duarte, ampliada a la José Martí. En este sub-sector, la institución pública más importante la constituye la escuela República del Uruguay, en la calle Caracas, muy próxima al parque Enriquillo, pues ocupa toda una manzana urbana, entre la Barahona y la Caracas, a excepción de las franjas ocupadas desde hace décadas por viviendas en la Juana Saltitopa y la José Martí.

En esta zona, de donde mayormente proceden los niños y niñas de la escuela Uruguay, junto a niños y niñas de Borojol, predominan las viviendas de madera, con un alto número de patios. Sólamente en las cuatro manzanas comprendidas entre la Ravelo y la Barahona, y entre la José Martí y la Doctor Betances, contabilizamos hasta 22 entradas a patios y callejones que albergan un amplio conglomerado de familias.

Este nivel de deterioro humano y social se agudiza, al ser la zona donde es más notable la especulación salvaje del suelo, reflejada en la aparición de numerosos solares adquiridos con fines de ampliar la extensión de las superficies comerciales, o con otros fines, y que despueblan de familias también este área de Villa Francisca. La misma escuela está siendo rodeada por esta especulación, pues en casi todos sus frentes existen ya solares de los que se utilizan como parqueos, y que ya hemos comentado en este trabajo.

El extremo norte y sur de este sector, flanqueado por las avenidas París y Méjico, respectivamente, presenta la hilera de bloques de apartamentos que ya hemos comentado, y que desarrolla otro tipo de habitat diferente, como en la esquina de la Jácuba con la Francisco Henríquez, que algunos lugareños denominan con gracejo zona apache, dado el clima propio que crea la presencia de grupos de jóvenes que desarrollan una cultura de osten- 
tación de la agresividad. Otro grupo excluido que deambula esta zona es de el de los niños y niñas de la calle. o palomos, que junto a otras personas transeúntes confluyen a veces en el Parque Enriquillo, ofreciendo una dramática semblanza del más profundo abandono humano.

Cerca del Parque Enriquillo, hacia la José Martí, se encuentra el único consultorio médico público y botica popular del sector, en el edificio del sindicato POASI. El otro consultorio médico no es de acceso universal, pues es para afiliados del Instituto Dominicano de Seguros Sociales (IDSS), ubicado en la calle Josefa Brea.

En el límite noroeste de este sub-sector se encuentra el centro de atención temprana más importante del sector, la guardería de las Hijas de la Caridad, en la esquina de la José Martí con 27 de Febrero, que constituye el único servicio de estas características.

Entre la Duarte y su extremo Este es donde más pequeños centros educativos, o escuelas de carácter privado, hemos podido documentar, destacando entre ellas, la ubicada en el Parque Enriquillo, junto al destacamento policial, y la de Isa, en la calle Las Honradas, entre las más afamadas. Estas escuelas suelen desarrollar un auténtico papel compensatorio, para niños y niñas excluídos de la escuela regular por dificultades diversas de aprendizaje o simplemente para alfabetización inicial, siendo muy valoradas por las familias.

También en esta zona es posible encontrar ofertas de academias de estudios técnicos no formales, como el Centro Cristiano que funciona en horario sabatino en el propio local de la escuela.

Varias de las calles de esta zona, especialmente las más próximas a la confluencia París-Duarte-Parque Enriquillo se hallan ocupadas por paradas de guaguas, en plena calle, o bien en pequeñas y a veces poco higiénicas terminales de pasajeros, para el transporte al interior del país. Esta es una de las características de 
la entrada principal de la escuela, parcialmente invadida por estacionamiento de guaguas.

Por último, no podemos dejar de describir las características de este sub-sector, sin aludir a la intervención del Estado en relación a la regulación de la venta ambulante, representada en el enorme edificio de cuatro plantas denominado "Plaza Buhoneros". Pensado para albergar a los y las vendedoresy vendendoras callejeros de toda índole, tal y como se concentró la venta de artesanías en el Mercado Modelo, constituye un ejemplo de cómo el diseño de una solución desde el Estado, o su incapacidad para negociar con los intereses en juego, frustra cualquier salida a una situación. Situado en una zona de tránsito diario de miles de gentes de paso, sólo una minoría del comercio ambulante ha aceptado trasladar su puesto a uno de los pasillos de la monumental construcción (ocupa la mitad de una cuadra) edificada "para ellos".

A pesar de su función social, la dialéctica vendedores y vendedoras ambulantes-autoridades (policia), oscila entre la permisividad habitual y el hostigamiento esporádico, cuando es necesario implantar algunas medidas, como facilitar el tránsito vehicular.

\section{MAPA SOCIAL IV - BOROJOL, ENTRE EL MITO Y EL AISLAMIENTO}

Al Este de la Vicente Noble, hasta el límite del río, Borojol, o Ensanche Margara. Todo este segmento urbano entre la Vicente Noble (nombre del pueblo natal de Lucrecia Pérez) y la Rafael Atoa, y entre la Loma del Chivo y Timbeque, constituye el extremo más oriental de Villa Francisca, pero, como en el caso de su extremo más occidental, que se confunde con San Carlos, también aquí las percepciones disienten de la cartografía oficial, con la diferencia de que, en el caso comentado, tanto las familias de 
aquél sub-sector, como las de zonas externas a él, coinciden en un gran número de casos en que se trata de San Carlos.

Sin embargo, la percepción es diferente para muchas familias al Este y al Oeste de la Vicente Noble, o sea, dentro o fuera del arrabal. Para las familias de fuera, el sub-sector ya no pertenecería a Villa Francisca, siendo Borojol la denominación más aceptada, que en realidad es una pequeña zona al otro lado de la Vicente Noble con Respaldo Ravelo, mítica por la proliferación hace décadas de cabarets donde se bebía y bailaba Son. Sin embargo, todo el arrabal que se fue formando adquirió la denominación de Borojol, tal vez adscribiéndole peyorativamente etiquetas de mal vivir.

Muchas familias del arrabal, sin embargo, aunque aceptan ser de Borojol, entienden formar parte de Villa Francisca, en un modo que interpretamos ser un intento más de no ser excluidas. Un nativo de la zona, nos aclaraba, además, que el nombre real del sector es el de Ensanche Margara, aludiendo a la ubicación real del Borojol de los soneros, y como intento de evadir esa etiqueta.

A pesar de que en diversas zonas de Villa Francisca es frecuente la intervención de la policía frente a grupos o personas en actividades en conflicto con la ley, como el tráfico de drogas. esta zona soporta el mayor prejuicio al respecto, como conflictiva y caliente. Sin querer establecer ningún tipo de relación causal no examinada con detalle, sí es cierto que en esta zona los callejones tienen más extensión y conforman auténticas redes que materializan un hacinamiento extremo. También es la zona más próxima a Guachupita, un núcleo complejo de situaciones en conflicto con la ley y de protesta social.

Paradójicamente, de todas las áreas analizadas de Villa Francisca, la que incluye espacios de mayor amplitud y tranquilidad para la recreación de los niños, niñas y sus familias, es ésta de Borojol, probablemente por estar situada al margen de las gran- 
des vías del tránsito rodado. El hecho de no tener salida a la cornisa fluvial las calles en dirección Este. debido al muro ya mencionado que separa el barrio del río, favorece que los niños y niñas puedan jugar sin temor a ser atropellados, especialmente en la calle Ravelo, relativamente ancha, y en su confluencia con la Yolanda Guzmán y Las Honradas. En ese espacio incluso, la escasa circulación se cierra a veces para desarrollar actividades del club de pelota de mano, lo cual ofrece posibilidades para la habilitación de un parque infantil.

Este dato sin embargo, tiene el contrapunto, grave, de la elevada contaminación, acústica y de otra índole, que arroja la planta de energía eléctrica de Timbeque, que, aunque favorece la permanencia del fluido eléctrico al área, distorsiona la salud medioambiental precisamente de las familias que viven en condiciones más hacinadas, en la parte final de la Ravelo, y por tanto, más próxima a la planta. Esta planta, de propiedad estatal, de la Corporación Dominicana de electricidad (CDE), data de la época de Trujillo, y es más contaminante que las más modernas plantas Sea Board, propiedad de empresas que suministran su energía al Estado.

Sobre la mejora de su calidad de vida, Borojol, la única zona de esta margen de la ria Ozama, junto con la vecina Santa Bárbara, que ha perdido su acceso directo al río, soporta la misma excusa por parte del Estado, de posponer o evitar el debate sobre la solución de sus problemáticas, al tratarse de viviendas construídas "ilegalmente", o hallarse todo el sub-sector bajo amenaza y promesa - permanente- de desalojo, dada su insalubridad. En este sentido, Borojol viviría la misma situación de los restantes barrios ribereños del Ozama, pero sin la identidad vecinal y organizativa que caracteriza a otros. 
Al Sur de la avenida Méjico, hasta la avenida Mella. el sub-sector que se abre es una estrecha franja creada artificialmente, al abrir la avenida, tal y como comentábamos en este mismo trabajo.

Toda la zona refleja la decadencia derivada del desplazamiento de la actividad comercial más competitiva a otras zonas de la Duarte o de la ciudad, a pesar de lo cual su frontera sur de la avenida Mella aún conserva su pujanza. En torno a esa vía, junto a un variado sector minorista, existen algunas grandes superficies, y la presencia cercana del Mercado Modelo, con artesanías para turistas, y el mercado paralelo de frutas, verduras y flores al aire libre, ya fuera del perímetro de Villa Francisca, pero que irradian a las calles a su alrededor un intenso movimiento humano y económico.

A medida que nos aproximamos al entorno de esos mercados, es abundante la ocupación de los locales con fines de almacén, así como el desplazamiento de camiones en labores de carga y descarga. La actividad comercial del sector se halla relacionada con la presencia del área conocida como "Pequeño Haití", por la alta concentración de personas de esta procedencia, quienes protagonizan, dentro del perímetro de Villa Francisca y en el del barrio colindante, patéticas situaciones de hacinamiento en las llamadas cuarterias, o viviendas compartimentalizadas en cuartos (pequeñas habitaciones).

También esta frontera sur de Villa Francisca, congestionada igualmente por dos concurridas vías de transporte urbano, sufre el efecto de la sobre-ocupación comercial de su superficie, lo que altera el equilibrio residencial y origina que, al igual que en el resto de la Duarte, al caer la noche y cerrar los comercios, la avenida Mella y sus calles aledañas se conviertan en un área siniestra, solitaria, oscura, y peligrosa. En ese horario permanecen abiertas algunas salas de diversión nocturna. 
Por la antigüedad de este sub-sector y su decadencia socioeconómica, las edificaciones ofrecen un aspecto de deterioro notable, a pesar de ser de «concreto» en un gran número, al menos la fachada. Esta situación es más evidente en las cuadras comprendidas entre la José Martí y el parque de Santa Bárbara. donde las condiciones de marginalidad se acentúan por la incapacidad de las familias para reparar viviendas de estas características, hasta históricas, y donde los establecimientos comerciales, sencillamente, han emigrado.

Un caso notable en este sentido, lo constituye el edificio de la "Casa Zaglul", próspero negocio familiar de la época de Trujillo, cuyos propietarios levantaron la construcción más alta y voluminosa de la zona, como apartamentos para familias acomodadas. Durante más de treinta años, sucesivas ventas y sub-arriendos han multiplicado el número de habitantes en la edificación, a la par que se iban deteriorando sus servicios, creando un inverosímil laberinto de familias, similar al de los numerosos patios de Villa Francisca, pero en vertical.

Por último, cabe citar que en el șub-sector este de Villa Francisca fue donde encontramos discrepancias más graves entre el mapa de la ONE y el mapa real, pues hay una calle que no aparece reflejada en el mapa, la Pimentel (ubicada donde aparece en el mapa la Benigno del Castillo), mientras que la Álvaro García se halla rotulada como Álvaro Garabito, que es como se la conoce. Sobre el plano, una calle aparece repetida en el mismo sector, la Cuba, pero en realidad sucede que una de ellas dos, la situada entre la Doctor Betances y la Josefa Brea, en realidad es la Jácuba.

Estas discrepancias tienen que ver no sólo con escasa pulcritud en los levantamientos de datos, sino también con incoherencias entre la administración que rotula las calles, el Ayuntamiento, y la oficina nacional que levanta planos topométricos, la ONE. Otra fuente de dificultad para la identificación de cada calle proviene del hecho de que una misma calle cambia su denominación 
en algún punto de su trazado, no hay correlación estricta entre los números de las viviendas, o bien la numeración se reinicia en algún punto de la misma calle como sucede en la Doctor Betances.

\section{Comprensión de los Mapas Sociales de Villa Francisca en el Contexto Socio-económico Nacional}

Las estadísticas de ONAPLAN referidas a la focalización de la pobreza en la República Dominicana sitúan a Villa Francisca entre los 10 barrios más pobres de Santo Domingo (de un total de 93 barrios, y una población de 2,500,000 personas), a partir de datos del Censo nacional de población de 1993, analizados y publicados por este organismo del Estado a fines de 1997, a falta de datos confiables de mayor actualidad. La descripción del proceso de crecimiento desigual y desarraigo humano en Villa Francisca, que acabamos de describir en este trabajo, nos permite entender que no existen condiciones para la mejora de las condiciones planteadas en 1993, sino más bien todo lo contrario, en relación a dimensiones integrales de calidad de vida. La misma fuente cifra en cerca de un 56\% los hogares pobres en República Dominicana (más de un millón), y, en cerca de 350,000, un 19\%, los hogares sumidos en pobreza extrema.

Las dimensiones utilizadas por ONAPLAN para describir la pobreza, son para la zona urbana,

a) vivienda y servicios básicos,

b) capacidad de sustento familiar.

c) capital humano y género, y

d) exclusión social.

Para el Distrito Nacional, del que forma parte preponderante la ciudad de Santo Domingo, según datos de 1993, las necesidades básicas mayormente expresadas son:

- Habitacionales, en relación a la necesidad de superar el hacinamiento, en hogares con 3 ó más personas por dor- 
mitorio (supera en un $50 \%$ a la percepción de cualquier otra necesidad), dentro de la dimensión a).

- De servicio sanitario adecuado, en hogares con inodoro colectivo, con letrina colectiva, o que no tiene servicio (supera en más de un $40 \%$ a la percepción de cualquier otra necesidad, muy cerca de la recogida de basura y agua potable), también dentro de la dimensión a)

- De capital humano, en hogares en que la educación de la persona jefe de hogar, o la educación media del hogar, para miembros mayores de 11 años de edad, es de 40 menos años de educación (supera en casi un $60 \%$ la percepción de cualquier otra necesidad), dentro de la dimensión $c$ ).

Estos datos se complementan y amplían con los de un reciente estudio realizado por el Fondo Nacional de Vivienda Popular (FONDOVIP) entre agosto y septiembre del 2000, reseñado en el periódico Hoy, en su edición del 16 de julio del 2001. Según esta organización, en República Dominicana 1,200,000 hogares presentan déficits en su estructura, espacio y servicios, con una ocupación promedio de 4.5 personas/ hogar, siendo un $37.6 \%$ los hogares que comparten servicios con otras viviendas $(32.1 \%$, baños; $23 \%$, patio; $2 \%$, cocina; $6 \%$, lavadero), y un $21 \%$ de aquéllos, casas de vecindad, cuarterías o barracones. Un $60 \%$ de las viviendas dominicanas, según este estudio, tiene la letrina como único servicio, y un $85 \%$ tiene en el alcantarillado su principal déficit, siendo 252,459 los hogares sin conexión a acueducto.

Según el censo de 1993, el $66 \%$ de las viviendas de Villa Francisca son individuales, el $57 \%$, de madera, y un $43 \%$ de block, estando cobijadas de zinc con piso de cemento más del $70 \%$. El servicio de electricidad era recibido por el $36 \%$ de las viviendas desde llaves públicas, y el $27 \%$ de otro lugar, concentrándose una incesante actividad de búsqueda de agua en los pun- 
tos adonde llega de modo regular, como la calle Licey en el sector Este de Villa Francisca.

Las instalaciones sanitarias se distribuyen en un $43 \%$ con servicio de inodoro individual, $32 \%$ inodoro de uso colectivo, $21 \%$ letrinas, y $4 \%$ no tiene.

República Dominicana es el octavo país más pobre de América Latina, ocupando el puesto 86 en la clasificación del índice de Desarrollo Humano del Programa de las Naciones Unidas para el Desarrollo (PNUD) correspondiente al 2001, descendiendo un puesto respecto a la clasificación del 2,000, hallándose la esperanza de vida en 67.2 años. En el Caribe sólo Haití se halla por detrás en cuanto a desarrollo y calidad de vida. Todo esto a pesar de que en los últimos años, República Dominicana protagonizó un nivel de crecimiento económico sin precedentes. Este contraste nos parece notorio de reseñar, especialmente como metáfora, a nivel nacional, de la brecha social que se profundiza en Villa Francisca, en un país donde un $38 \%$ de la riqueza es acaparado por el $10 \%$, frente a un $12.9 \%$ para el $40 \%$ más pobre.

Para el propio Banco Mundial, según el estudio sobre la "Evolución de la pobreza y el gasto social en República Dominicana", presentado por el economista-jefe para América Latina, Guillermo Perry (julio 2001), la pobreza está asociada con menores niveles o con el uso limitado de activos como educación, tierra, crédito y servicios, junto con otros como el número de hijos/as, nivel educativo del jefe de hogar y empleo en sector informal, elementos visibles y/o cuestionados en Villa Francisca. Este mismo estudio, que reconoce que el porcentaje de la pobreza es "muy alto", de un $35 \%$, responsabiliza al escaso gasto social del Estado dominicano (un 1\% del PIB en 1998), y a su mala focalización y racionalización, parte de la situación.

Precisamente, en ese año al que se refiere el estudio del organismo, la parte norte de Villa Francisca era flanqueada por un costosísimo y extenso elevado para la circulación rodada, que, 
junto con otras construcciones similares, se convirtieron para la población en el símbolo de las opciones sociales del gobierno.

No obstante ser verdad que el gasto social del Estado dominicano es ínfimo, no es posible dejar de citar, a pesar de ser uno de los más bajos porcentajes del tercer mundo, que el servicio de la deuda externa del país, que tiene mucho que ver también con esas prioridades sociales, ha constituido un $5 \%$ de lo exportado por el país en bienes y servicios, según datos del Estado Mundial de la Infancia, anteriores, en este caso, a 1998. En cualquier caso, se sigue justificando el endeudamiento como única vía para acometer las inversiones sociales necesarias.

Según el Banco Central, la deuda externa dominicana asciende a la fecha a 3,675 millones de dólares, y actualmente el gobierno completa con la prevista emisión de "bonos soberanos" un proceso de empréstitos para recabar recursos para distintos programas, por un equivalente a un $45 \%$ de la actual deuda externa del país, unos 1,674 millones de dólares más. De ellos, 437 millones de dólares se han contraído con la banca española, y 500 millones se espera que se promulguen en concepto de "bonos soberanos".

En la percepción de gran parte de la población, el desempleo se sitúa como la causa principal de la pobreza (encuesta DEMOS97, una tercera parte de los/as encuestados/as) o el principal problema del país (Encuesta Hamilton/Hoy de 1999, con un 40\%). Las encuestas de población ENDESA 93 y 96 cifran el desempleo en un $26.2 \%$ y $37.6 \%$. Estas cifras tan altas contrastan con las ofrecidas por el Banco Central en aquel momento (19.6\% y $16.5 \%$ ), así como por el Banco Mundial referidas al 98 (13\%), siendo fuente de divergencias, aparte de sesgos metodológicos, las tasas correspondientes al trabajo de las mujeres, adolescentes y niños mayores de 10 años, así como las definiciones estándares de empleo.

En cualquier caso, como sucede en muchos otros países, el auge del nivel ocupacional que registra el sector informal, que 
FONDOMICRO cifra en unos 207,000 entre 1996 y 1998, nos permite entender que este sector constituye una válvula de escape de los efectos del desmantelamiento industrial en el sector público y de la desregulación del sector laboral, que caracteriza las políticas neoliberales, absorbiendo la numerosa mano de obra con escasa cualificación. En ese mismo período, las zonas francas absorbieron 30,000 empleos, aunque, sin embargo, los cierres de empresas en ese sector en el año 2000/2001 ponen de manifiesto la extrema volatilidad de esa fuente de generación de empleo intensivo, según "condiciones de mercado", al igual que ha sucedido con la ocupación laboral en el sector turístico.

La fragilidad de la estructura ocupacional dominicana se pone de manifiesto, finalmente, por cuanto, para 1996, el sector servicios representa un $27.2 \%$ de la PEA, y un $23.2 \%$ se adscribe al comercio, pero en condiciones que hacen poco competitivo, en términos salariales, al trabajador/a de estos sectores, cuyo crecimiento tan bien simboliza Villa Francisca. No en vano, a pesar de que la inversión extranjera directa pasó de 133 millones de dólares en 1990 a 430 en 1996, sucesivas encuestas confirman que más de la mitad de la población dominicana desea emigrar del país, constituyendo el aporte de la emigración la principal entrada de divisas, siendo la dominicana la tercera fuerza migratoria emergente en los Estados Unidos de Norteamérica.

Esta percepción nacional acerca del abandono de lo propio, ligada al deterioro de las condiciones de vida, es fácilmente comprensible en el caso de Villa Francisca, como un lugar que ya casi no es de nadie, con el que pocos/as se identifican, y del que muchos/as mejor prefieren salir. De hecho, los datos ofrecidos sobre densidad poblacional del sector, manifiestan un decrecimiento de 1.01, lo que sitúa la población de Villa Francisca en 28.824 habitantes. Este descenso poblacional es entendido por De La Cruz y Santana (2000) en función de las condiciones de los servicios sociales, como ya apuntábamos en este trabajo. 
Finalmente, para focalizar el desarrollo desde la niñez, es imprescindible que nos refiramos a la Tasa de Mortalidad de Niños y Niñas Menores de 5 años (TMM5), que sitúa a República Dominicana en el puesto 76 entre las naciones del mundo, con una disminución de esta tasa de un 65 por mil a un 49 por mil. Para el UNICEF el TMM5

"[...] está menos expuesta que el PNB per capita a la falacia del promedio estadístico (...); no existe una relación fija entre la tasa anual de reducción de la TMM5 y la tasa anual de crecimiento del PNB per capita" (Estado Mundial de la Infancia 2001). Para el UNICEF, "si se quiere que el desarrollo adquiera una imagen más humana [...] será necesario utilizar una medida tanto del progreso económico como humano."

\section{La Niñez y las Familias de Villa Francisca en el Marco del Neoliberalismo: Apuntes para una Intervención Socio-educativa}

La familia ha sido tradicionalmente objeto de análisis, debido a la necesidad de identificar en su seno a sujetos excluídos de políticas sociales : niños/as, mujeres, envejecientes, desempleados/as. En el caso de Villa Francisca, frente a una población adulta de un $63 \%$, la población de 0 a 14 años representa un $31 \%$, mientras que los/as envejecientes representan el $6 \%$.

Respecto a la pobreza, el estudio de 1997 de ONAPLAN referido a Villa Francisca, sitúa en un $45.8 \%$ los hogares pobres, o sea, unos 7,425 hogares. Las principales necesidades básicas insatisafechas son: acceso a agua potable $(90.2 \%)$, servicios sanitarios adecuados $(75.7 \%)$, y deficiencias habitacionales $(66.3 \%)$, lo cual, como ya señalamos, es coherente con las demandas más sentidas en el resto de los barrios de Santo Domingo.

La consideración de la vulnerabilidad de las familias se halla también referida a su nivel de satisfacción de la canasta alimentaria de cada uno de sus miembros, cifrada en RD $\$ 425$ 
por persona en el estudio de ONAPLAN de 1997, siendo éste el nivel al que se adscribe un $19 \%$ de las familias dominicanas, bajo situación de extrema pobreza o indigencia. En un nivel algo s!!perior, el $56 \%$ bajo la línea de la pobreza no llega a satisfacer adecuadamente la denominada canasta básica de consumo, que la misma fuente cifra en $\mathrm{RD} \$ 850$ por persona, y que incluye el acceso a otros bienes y servicios útiles para la vida, más allá de lo estrictamente alimentario. A este respecto, Tejada Holguín (1996) recoge los datos del CIECA (Centro de Investigaciones económicas del Caribe) sobre el significado de la inflación:

"El salario mínimo nominal de 1995 (RD\$1,400.00) tiene menos poder de compra que el salario de 1970 que era de RD $\$ 60.00$. ya que esos RD\$1,400.00 equivalen a unos RD\$41.00 de 1970."

Según el Censo de 1993 la desocupación en Villa Francisca alcanzaba un $17 \%$ de la PEA, siendo dueños de negocios un $3.6 \%$, trabajadores/as por cuenta propia y servicio doméstico un $22 \%$, y asalariados/as más del $50 \%$.

En cuanto al capital humano, que es otro de los factores señalados por ONAPLAN (1997) para entender la pobreza, los datos del mismo Censo nos informan de una tasa de analfabetismo del $11.1 \%$, habiendo realizado estudios primarios un $65 \%$, y un $28 \%$ estudios secundarios, técnicos y universitarios.

La consideración de estas cifras mediatiza, pues, ineludiblemente la realidad de las familias de Villa Francisca. como las de muchos otros sectores, y contiene numerosas implicaciones sociales que nos ayudan a entender aquéllas, y que resumimos en estos puntos:

a) La familia, espacio de identidad emocional y afectiva de personas de todas las edades, especialmente consistente en la atención temprana de niños/as, frente al acoso de realidades que están más allá de su control, está 
condicionada por el desarrollo de diversas estrategias de supervivencia.

b) La débil cualificación del "capital humano" de las familias, ligada a otras carencias de servicios, a la alta tasa de fecundidad y a factores asociados a la TMM5, contribuyen a reproducir la pobreza, por cuanto suponen una alta desigualdad de oportunidades, que se hallan relacionadas con el alto porcentaje de población asalariada de Villa Francisca, y empleada de hogar, que siempre devengan los salarios más bajos.

c) Las estrategias de supervivencia condicionan (como para muchas familias de clase media), las posibilidades de empleo del tiempo en la crianza de los hijos/as, y se hallan relacionadas con la movilidad de los roles en las familias, creándose sub-jefaturas efectivas de abuelas, tías, hermanas mayores, y más raramente, adultos varones y con la escasa cualificación (a menos preparación. es más posible más horas de trabajo por menor sueldo).

d) Estos diferentes modelos organizativos hacen más idóneo hablar de familias, en plural, en República Dominicana, que de "la familia", como unidad monolítica y homogénea.

e) El menor tiempo con los hijos/as fortalece la preponderancia de otros actores de socialización, entre los que destacan la calle/ barrio, y la televisión/ cultura audiovisual. Sin embargo, esta carencia constituye en sí una oportunidad para diseñar espacios recreativos y ofertas culturales para NNA en los barrios.

f) La familia humaniza nuestra comprensión del desarrollo y concretiza las dificultades y posibilidades asociadas a la viabilidad de éste, pues en su seno 
evolucionan variables como las relacionadas con la TMM5, ya comentada,

"[...] resultado de una amplia variedad de factores: salud nutricional y conocimientos básicos de salud de la madre: cobertura de inmunización y utilización de la TRO - Terapia de Rehidratación oral --: acceso a servicios de atención materno-infantil (incluida atención prenatal); niveles de ingresos y disponibilidad de alimentos de la familia; acceso a agua potable y saneamiento eficaz, $y$ grado de seguridad del medio ambiente infantil" (Estado Mundial de la Infancia 2001).

Empezamos abordando la historia y geografía de un sector muy popular, céntrico y conocido, para adentrarnos en la realidad de las personas, no tan conocida, que crea mapas sociales que dan sentido a cada fragmento urbano.

Como nos recuerda Cela (2000),

“[...] en estos tiempos de globalización en que nos perdemos en la inmensidad de los grandes proyectos, el barrio representa la afirmación de la persona".

Sobre todo para estas familias de Villa Francisca, que, generalmente, no tienen la capacidad de elegir su lugar de residencia. Por ello, la recuperación de lo barrial como espacio público, de identidad y ciudadanía, sin negar otros referentes externos, es un reto necesario e imprescindible, especialmente con estas familias, que no sólo viven la agresión de ver cuestionada su supervivencia a causa del modelo socio-económico imperante, sino que ven limitado su habitat territorial.

En nuestro sondeo e inmersión barrial con las familias de niños y niñas de la escuela, al referirse a las problemáticas más sentidas, la mayor parte de las familias expresan tanto la inseguridad ciudadana, como la dificultad de encontrar un espacio propio en el barrio. Esto tiene repercusión directa en la socialización de los NNA. 
Aunque Villa Francisca no está identificada entre los barrios más inseguros de Santo Domingo, sus vecinos sienten el impacto de actividades contra la ley y la convivencia. como robos y asaltos a viviendas y particulares, a veces relacionadas con actividades ligadas al narcotráfico, visible, asi como el consumo de droga, y las consecuentes redadas policiales.

Algunas personas aluden a adultos que utilizan a NNA para cometer delitos. y otras al clima moral perjudicial que este contexto supone.

Algunas de estas acciones son ejercidas por grupos de adolescentes y jóvenes pandilleros que se "apropian" simbólica y efectivamente de esquinas e intersecciones donde desarrollan diversos rituales de identidad que intimidan a otros lugareños. muchos de los cuales argumentan que los "tígueres no son del pedazo". Estos grupos a veces participan en protestas violentas por demandas sociales, como agua, luz. etc.. aunque, en este sentido. cl carácter reivindicativo del barrio ha perdido la fuerza legendaria de décadas atrás, como ya analizamos.

Como algunos vecinos reconocen, el desempleo está altamente relacionado con la frustración de estos jóvenes, que, sin embargo. especialmente, en un lugar como Villa Francisca, presencian a diario la seducción del consumo como valor que da seguridad y poder, cuando otras seguridades básicas han sido negadas.

En el caso del espacio infantil, las madres entrevistadas insisten en la necesidad de canchas, espacios para deportes y recreación. Algunas familias se esfuerzan en aprovechar el escaso tiempo libre del fin de semana en sacar a sus hijos/as a divertirse. pero estos desplazamientos, aún modestos. están limitados por las posibilidades económicas.

Para las personas adultas, también el barrio se vuelve hostil. debido a la división vecinal, por la cultura del chisme y la competencia. tal vez acentuada por el escaso tiempo de que dispone cada familia para convivir con otras. la presión del uso de servi- 
cios comunes y del hacinamiento, así como el deterioro de valores de convivencia, por todo ello. Incluso, dentro de la propia familia, muchas veces las relaciones se tornan agresivas y desconfiadas, no sólo por la perpetuación del machismo, sino por la inestabilidad conyugal, que introduce nuevos actores. sobre todo en la crianza de los NNA, a través de nuevas parejas. Este elemento (los padrastros), unido al hacinamiento contribuye a situaciones de abuso a todos los niveles, físico. sexual y psíquico.

Un tercer elemento citado frecuentemente se refiere a la invasión del espacio público por el tránsito vehicular. que. aunque no afecta por igual a todas las zonas de Villa Francisca, se percibe más incontrolable, por la posición del sector como nudo de comunicación, y el poder de los sindicatos de transportistas.

Todo este cúmulo de situaciones provoca, finalmente, que los niños y niñas y sus familias vivan con un alto índice de temor, y eviten a veces hacer uso del espacio común ciudadano de la calle, replegándose en la intimidad de los patios y callejones. tan abundantes en Villa Francisca. en los tiempos libres que el trabajo permite, no obstante hallarse acostumbrados/as a tal situación. Muchos niños y niñas, pues, viven "presos" en su propio barrio, viendo severamente limitado su derecho a la recreación.

Estas situaciones de exclusión se relacionan, pues, con procesos de pérdida acelerada de identidad en el sector, La pérdida de identidad es a la vez causa y efecto, pues. como pocos/as se sienten realmente parte del barrio, casi nadie se siente en capacidad o con motivación de hacer algo a favor de la comunidad y la mejora de su calidad de vida. Al tener negada la posibilidad de un espacio propio, como señala Cela (1998), el espacio colectivo no se entiende como tal, sino como ajeno mientras no es privatizado (por otro más poderoso). En suma. el espacio colectivo lo convierto en propio, sin sentirme responsable de su cuidado (pues no tengo ningún poder sobre él), porque es una extensión de mi 
espacio vital, tal y como se pone de manifiesto desde la escuela hasta el desempeño en la venta ambulante.

¿Conocerán las familias de Villa Francisca la posibilidad de encontrar un espacio vital sobre el territorio donde muchas de ellas han crecido, basado en una identidad común?

Tal vez esta pregunta se la hace hoy una mamá que jugaba de pequeña en el Parque Enriquillo, y que nos confesaba que

"se burlaban de mí las vecinas... tú lo crías a tu hijo como especial... lo quería aislar. A veces una quisiera encerrar a sus hijos en una jaula para que no les afecte lo que hay. ¿Y cuál va a ser la sociedad del futuro de mis hijos?"

\section{BIBLIOGRAFÍA}

ALEMAN, J. L. (1998). Globalización económica y sus consecuencias sociales y éticas, en Estudios Sociales, N. ${ }^{\circ} 111$, enero-marzo. Santo Domingo, CES.

AA. VV. (1997). Focalización de la pobreza en la República Dominicana, en Informe Población. N. ${ }^{\circ} 11$, diciembre. Santo Domingo, Oficina Naacional de Planificación (ONAPLÁN).

AA. VV. (1998). Ley $N{ }^{\circ}$ 14-94. Código para la protección de Niños, Niñas y Adolescentes/Convención internacional de los Derechos del Niño. Santo Domingo, Organismo Rector.

BARRIUSO, A., et al (2000). "Sólo paños tibios contra la pobreza", en Ahora, N. ${ }^{\circ} 1162$.

CELA, J. (1998). La otra cara de la pobreza. Santo.Domingo, CES. $2^{\text {a }}$ edición.

CELA, J. (2000). Del barrio a la ciudad pasando por la sociedad civil, en Estudios Sociales, N. ${ }^{\circ} 120$, abril-junio. Santo Domingo, CES.

DE LA CRUZ, D. y SANTANA, M. (2000). Estudio socio-económico, Zona Colonial, Villa Francisca, Villa Duarte. Santo Domingo, ProAmbiente. Mimeo.

MAX-NEEF, M.(1993) : Desarrollo a escala humana. Conceptos, aplicaciones y algunas reflexiones. Montevideo, Nordan-Comunidad/ REDEs. 
PEREZ, C. (1996). Urhanización y municipio en Santo Domingo. Santo Domingo, INTEC.

PILOTTI, F. (1995). Crisis y perspectivas del sistema de bienestar infantil en América Latina, en AA.VV. Derecho a tener derecho. Infancia, Derecho y Politicas sociales en Am. Lat. UNICEF/TACRO-I.I.N., Caracas, Vol. I.

TEJADA HOLGUIN, R. (1996). «La familia y las familias», en Estudios Sociales, N. ${ }^{\circ} 105$, julio-septiembre. Santo Domingo, CES.

VARGAS, T. (1998). De la casa a la calle. Estudio de la familiay vecindad en un bario de Santo Domingo.

ZAITER, J. (1996). La familia en República Dominicana, en Maestras y maestros: prácticas y cambio, $\mathrm{N} .^{\circ} 20$, agosto. 